OPEN

SUBJECT AREAS:

CONSERVATION

PHENOLOGY

ECOSYSTEM ECOLOGY

BIODIVERSITY

Received

8 January 2013

Accepted

20 February 2013

Published

15 March 2013

Correspondence and requests for materials should be addressed to

R.D. (r.danovaro@ univpm.it)

\section{Red coral extinction risk enhanced by ocean acidification}

\author{
Carlo Cerrano, Ulisse Cardini, Silvia Bianchelli, Cinzia Corinaldesi, Antonio Pusceddu \& Roberto Danovaro
}

Department of Life and Environmental Sciences, Polytechnic University of Marche, Ancona, Italy.

The red coral Corallium rubrum is a habitat-forming species with a prominent and structural role in mesophotic habitats, which sustains biodiversity hotspots. This precious coral is threatened by both over-exploitation and temperature driven mass mortality events. We report here that biocalcification, growth rates and polyps' (feeding) activity of Corallium rubrum are significantly reduced at $\mathrm{pCO}_{2}$ scenarios predicted for the end of this century $(0.2 \mathrm{pH}$ decrease). Since $C$. rubrum is a long-living species ( $>200$ years), our results suggest that ocean acidification predicted for 2100 will significantly increases the risk of extinction of present populations. Given the functional role of these corals in the mesophotic zone, we predict that ocean acidification might have cascading effects on the functioning of these habitats worldwide.

he precious red coral (Corallium rubrum, L. 1758) (Supplementary Figure S1) is one of the key engineering species of coralligenous systems (i.e., calcareous biogenic formations representing the richest biodiversity hard bottom habitat of the Mediterranean and other temperate seas) ${ }^{1,2}$. Historical documents suggest that $C$. rubrum was very common in the Mediterranean Sea ${ }^{3}$ along a wide bathymetric range, from 3 to more than $800 \mathrm{~m}$ depth $^{4,5}$. In the past it was easily harvestable also in shallow waters ${ }^{6}$ characterized by dim light habitats as coralligenous rims, overhanging rocky roofs, and marine caves. This species is currently threatened mainly by over-exploitation and climate-driven mass-mortality events and, at present, is commercially exploitable only at depth $>80 \mathrm{~m}$. C. rubrum is a long-living and slow-growing species, whose colonies can reach a size of a $40-50 \mathrm{~cm}$ height in about 200 years $^{1}$. Long-living species like C. rubrum stabilize the structure and play a key role in the functioning of many sub-littoral communities ${ }^{6}$. Stable habitats like the coralligenous, in turn, trigger positive feedbacks on the fitness of long-living species, which, over time, become even more important in habitat formation and maintenance. Habitat complexity also influences the maturity of deep-sea ecosystems and increases the ratio between biomass and productivity ${ }^{7}$. Finally, habitat complexity is strictly related to biodiversity $^{8}$, which in turn is linked to deep-sea ecosystem functioning ${ }^{9}$. Declines in the abundance of long-living and habitat-forming species can therefore lead to a rapid fragmentation in community structure, species and habitat loss, depressing ecosystem functioning and compromising meta-population connectivity ${ }^{10}$. In pristine habitats of the past, C. rubrum populations were characterized by a large size and high density of the colonies ${ }^{11}$, which created highly diverse and stable faunal assemblages. Red corals overexploitation and mass mortality events have reduced its distribution in the Mediterranean Sea and in the Western Pacific Ocean, and determined some cases of local extinctions ${ }^{11}$.

Ocean acidification represents an additional major threat for these calcifying species given its potential effects on growth rates, reproduction and resistance to environmental changes ${ }^{12}$. With increasing $\mathrm{pCO}_{2}$, reduced calcification rates have been observed for a variety of calcareous organisms even when aragonite or calcite saturation exceeds $1.0^{13-15}$. However, the sensitivity of marine organisms to acidification varies among different taxa and some species may increase calcification rates with increasing $\mathrm{CO}_{2}$ levels ${ }^{16,17}$. Still, studies on the response of calcification to ocean acidification have been conducted on a limited number of calcifying species ${ }^{17-20}$. Laboratory experiments on the effects of increased $\mathrm{pCO}_{2}$ on calcifying organisms have to be taken with caution due to the intrinsic limitations ${ }^{21}$, but they enable to control environmental variables allowing to assess the speciesspecific response to increasing $\mathrm{CO}_{2}$ levels ${ }^{22}$.

The Mediterranean Sea is a semi-enclosed, miniature ocean, which is expected to anticipate the impact of global climate change in the oceans ${ }^{23,24}$. Mediterranean waters (from surface to bathyal depths) show a clear acidification trend, and since the beginning of the industrial era a reduction of 0.05 to $0.14 \mathrm{pH}$ units has been reported ${ }^{23}$. Here we investigated, by means of short- and long-term laboratory experiments, the response of C. rubrum to increases in $\mathrm{pCO}_{2}$ in the range predicted for 2100 by the Intergovernmental Panel on Climate Change ${ }^{25}$. 


\section{Results}

Physical-chemical variables, carbonate parameters and microbiological variables. During the entire duration of the experiments, temperature and salinity were kept at the values recorded during sampling at $40 \mathrm{~m}$ depth (Supplementary Table S1). Both at the start and the end of the experiments all mesocosms displayed similar values of total alkalinity (coefficient of variation, CV 1.1\% and $1.6 \%$, respectively), DIC (1.2 and $1.8 \%$ respectively), and $\mathrm{HCO}_{3}{ }^{-}$(1.2 and 2.3\%, respectively). The treatment resulted in environmental conditions (including $\mathrm{pH}$ values, Supplementary Figure S2) able to mimic with high accuracy the conditions that are assumed to occur in the future if $\mathrm{CO}_{2}$ emissions continue at current rates $^{25}$. The food supply did not alter the concentrations of inorganic nutrients (determined only in the long-term experiment), which in treated mesocosms, at the end of the experiment, did not change significantly from those in the controls (Supplementary Figure S3). Moreover, since it is known that stressing environmental conditions can promote coral diseases ${ }^{26}$, prokaryotic and viral abundances were monitored during the entire duration of the experiment to ensure that changes in polyps' activity or eventual mortality were not ascribed to the outbreak of pathogenic infections ${ }^{27}$. Data collected indicate that there was no alteration in the analyzed microbiological variables (Supplementary Figure S4).

Coral growth. Colonies' buoyant weight was tightly correlated with their axial skeleton dry weight and their total skeleton dry weight (i.e., scleraxis plus sclerites) indicating the accuracy and reliability of the adopted protocol (Supplementary Figure S5a,b). Since for slowgrowing species, such as C. rubrum, accurate measurements of buoyant weight are generally achieved after long-term treatments, we only report here the results from the second experiment. Measured changes in buoyant weight were generally in the order of tens of milligrams, always well above the repeatability of the scale $( \pm 0.03 \mathrm{mg}$ ). Colonies mean growth rates (normalized to initial buoyant weights as \% difference day ${ }^{-1}$ ) estimated over the entire duration of the experiment (45 days) were $0.059 \pm 0.041,-0.064$ \pm 0.024 and $-0.032 \pm 0.026 \%$ day $^{-1}$ in the control and in the two acidified treatments respectively. Data of growth rate were also expressed as $\mathrm{mm} \mathrm{y}^{-1}$ (Supplementary Table S2). At all time intervals values in the control were significantly different (generally higher; Supplementary Table S3) than those in both acidified mesocosms (Figure 1).

Coral calcification. Differences in coral calcification have been assessed during the first experiment by comparing the relative abundance (as percentage) of the two different types (cross and capstain) of newly-accreted sclerites (i.e., fluorescent sclerites under epifluorescence microscope after inoculation of calcein) in the three experimental conditions (i.e. at 8.08, 7.88 and $7.77 \mathrm{pH}$ ) (Figure 2). The results of the experiments, were also evident from SEM analyses (Figure 3 and 4). Visual inspections of the morphology and integrity of the skeletal structures under SEM revealed that both

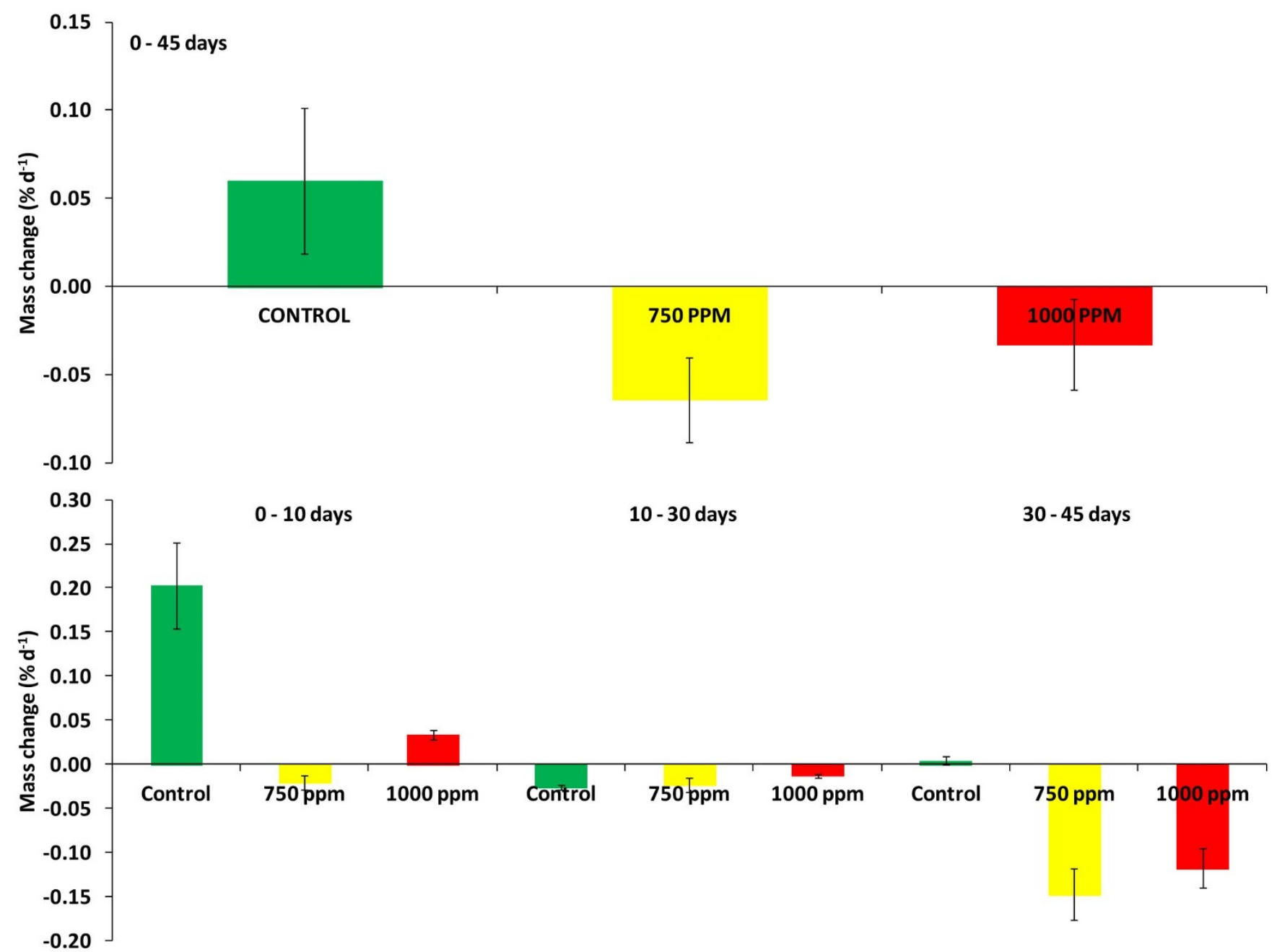

Figure 1 Daily mass change (\%) of coral colonies exposed to different levels of acidification compared to control conditions. Illustrated are changes estimated for the entire duration of the long-term experiment (0-45 days) (a) and for different time intervals (0-10, 10-30 and 30-45 days) (b). 

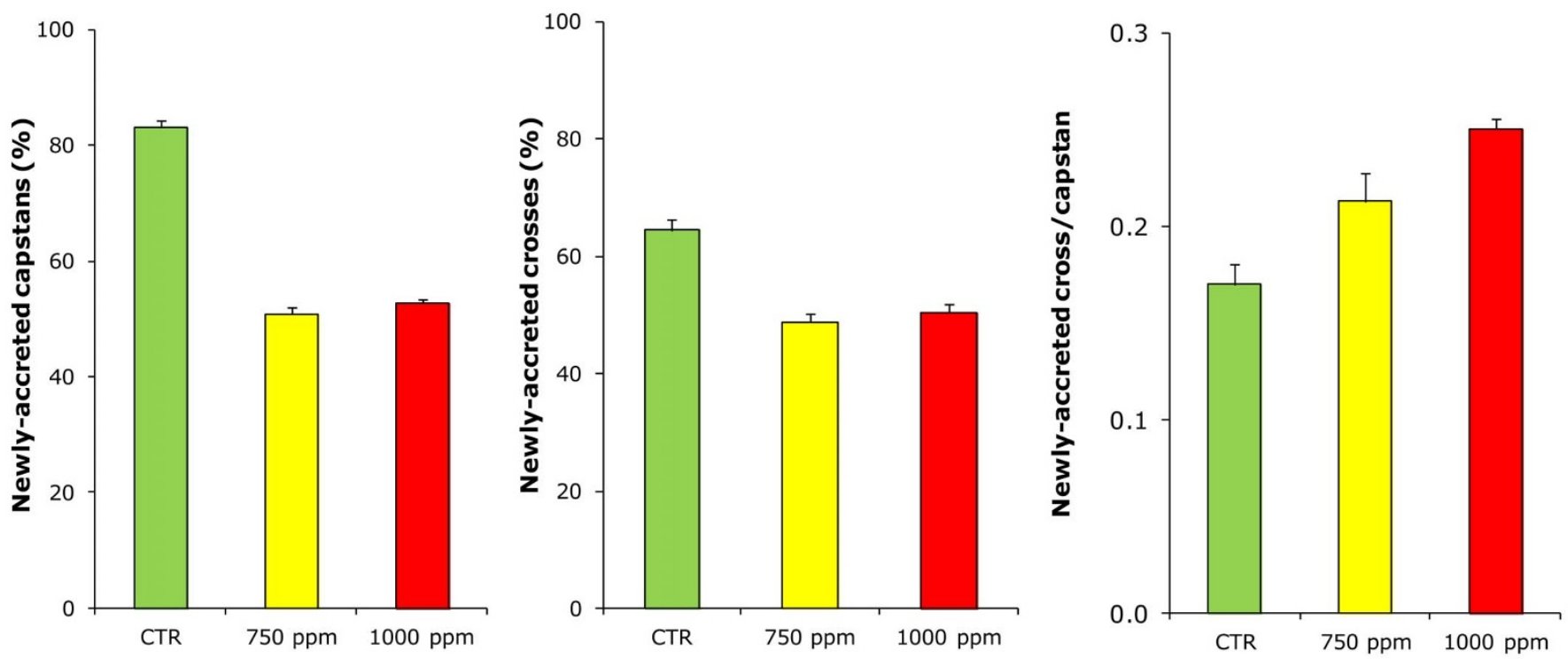

Figure $2 \mid$ Relative abundance (\%) of cross and capstain newly-accreted sclerites in the three experimental conditions.

the axial skeleton and the sclerites of colonies exposed to acidification appeared scraped when compared to those of colonies exposed to natural $\mathrm{pCO}_{2}$. To estimate the coral attitude to produce a preferential type of sclerites under different acidification levels we calculated the ratio of fluorescent cross to capstan sclerites. For all the above mentioned variables the one-way ANOVA revealed significant differences between the control and the acidified mesocosms; the pairwise tests revealed that in acidified mesocosms the number of newly-accreted sclerites, no matter the type, was significantly lower than in the control, whereas the cross to capstan ratio increased (Supplementary Table S4).

Polyps' activity. The coral's polyps activity and the percentage of open polyps overall did not exceed $40 \%$ and $70 \%$, respectively, even in the control mesocosms and the values reported from short-term and long-term experiments fluctuated in the same range (Figure 5). In particular, polyps' activity fluctuated around values reported for a healthy red coral population collected at similar or higher depths ${ }^{28}$. During the long-term experiment, to provide additional information

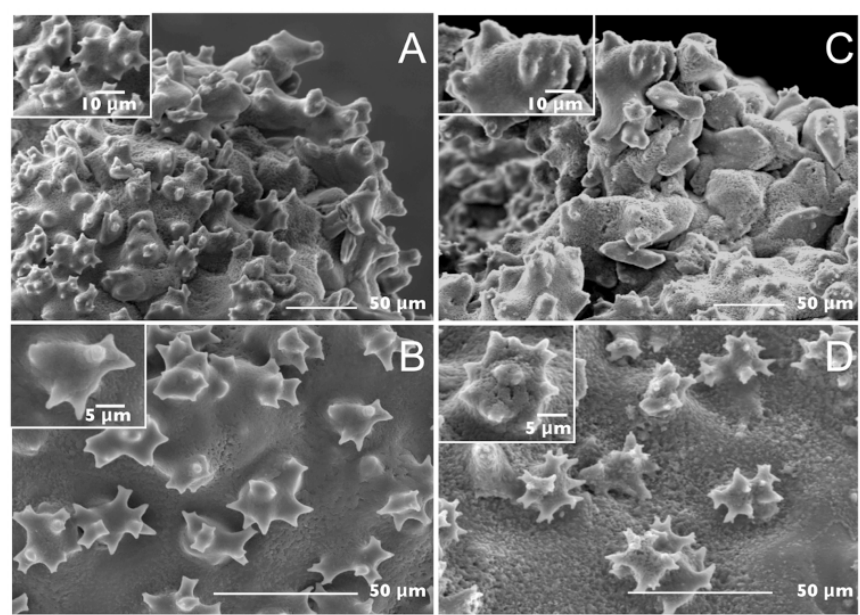

Figure 3 Comparison of axial skeleton structures of corals exposed to natural $\mathrm{pCO}_{2}$ and to acidification. (A), (B) the apex and the axial skeleton under natural conditions. (C), (D) the apex and the axial skeleton under acidified conditions. In the insets a detail for each phase. of the health status of the colonies, we also performed measurements of the percentage of open polyps. The repeated measures ANOVA reveal that, even if time had a considerable effect on the observed differences among treatments, both polyps' activity and the percentage of open polyps varied significantly among treatments (Supplementary Table S5) and, during the last 10 days of the experiment, showed values in the control mesocosms consistently and significantly higher than those measured in both acidified conditions.

\section{Discussion}

Changes in carbonate chemistry expected for the next decades will negatively affect a wide range of organisms ${ }^{14,29-32}$ allowing to foresee an impressive shifting in both benthic and pelagic taxa and in several habitats and biomes ${ }^{18,33}$. The response towards acidification will be different depending on the species, their phenology, their depth range. Deep-sea species are likely to be largely affected by global
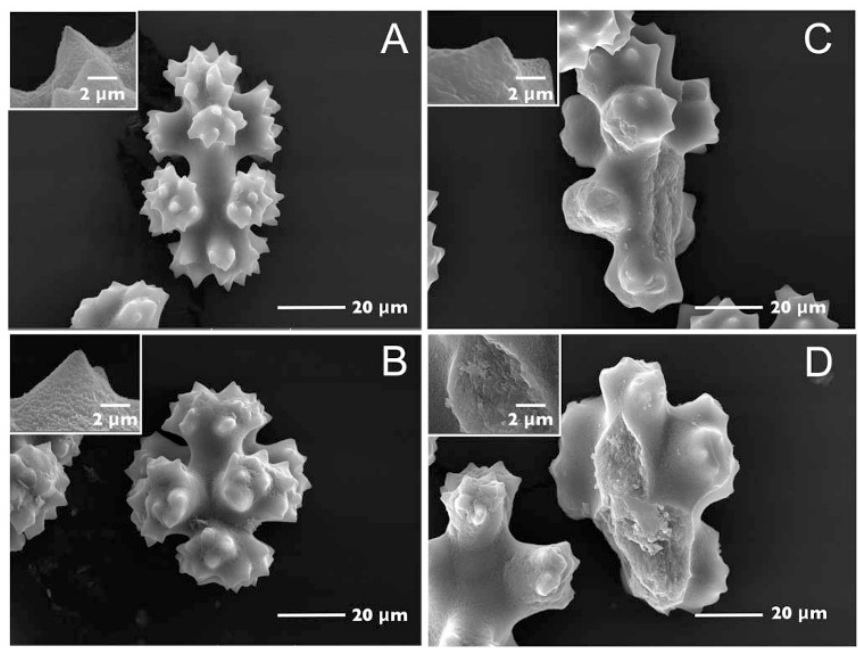

Figure $4 \mid$ Comparison of the two types of coral sclerites exposed to natural $\mathrm{pCO}_{2}$ and to acidification. (A),(B) capstan and cross-shaped sclerites under natural conditions, respectively. (C),(D) capstan and cross-shaped sclerites under acidified conditions, respectively with evident signs of altered calcification. In the insets a detail for each phase. 


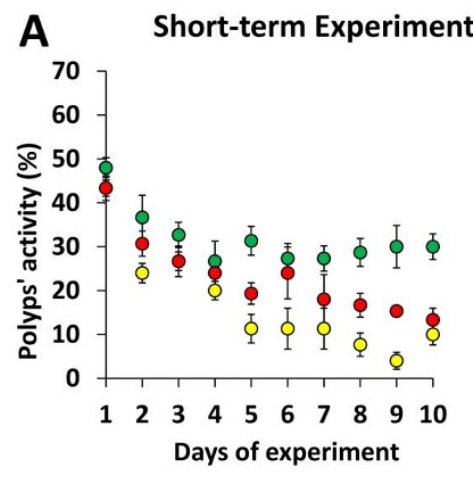

B

\section{Long-term experiment}
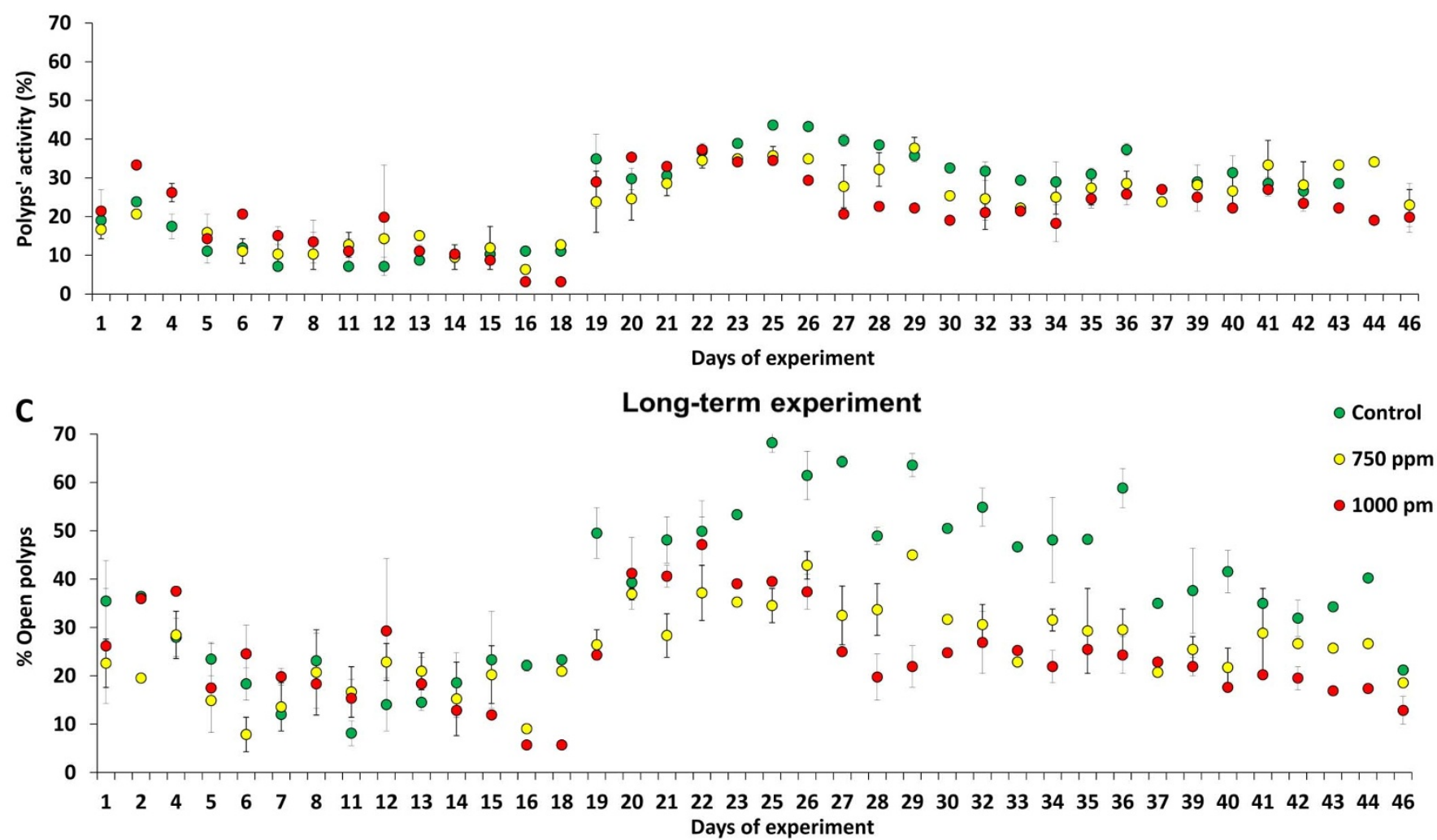

Figure $5 \mid$ Coral's polyps activity and the percentage of open polyps in the three treatments during the short- and long-term experiments.

climate change (by temperature shifts) and ocean acidification (either as $\mathrm{pH}$ decrease and changes in the global-mean depth of calcite and aragonite saturation horizons ${ }^{14}$ ). The skeleton of $C$. rubrum is built of high $\mathrm{Mg}$-calcite ${ }^{34}$, which is more soluble than aragonite. Thus we expect this species, and especially its deep-water populations, to be sensitive to the anticipated future shoaling of saturation horizons due to increasing $\mathrm{pCO}_{2}$ levels ${ }^{35}$. The red coral C. rubrum is a long-lived octocoral with population densities as high as 500-1000 colonies $\mathrm{m}^{-2}$, but with commercial sizes now confined to the mesophotic and deep zone (100-800 $\mathrm{m}$ depth) due to its overexploitation at shallower depths ${ }^{36}$.

Here we show that ocean acidification at levels predicted by the IPCC scenarios for the end of the century has a significant negative impact on polyps' activity, growth and biocalcification of this species. In particular, we report that polyps' activity significantly decreased under lower $\mathrm{pH}$ conditions. The expansion of polyps by Anthozoa is energetically highly expensive ${ }^{37}$. Therefore, in natural environment polyps are expanded in presence of high water flows, which in turn generally means abundance of food and, at the same time, a fast removal of catabolites. Consequently, while expanded polyps clearly suggest a healthy condition of the colonies, decreasing activity of the coral polyps under acidification will imply also reduced feeding and respiration efficiencies ${ }^{37}$. Recent investigations have proven that the presence of coral forests controls food availability and benthic biodiversity in the mesophotic zone ${ }^{38}$. We can hypothesize that acidification, while reducing feeding efficiencies of the red coral, could also affect or modify patterns of biodiversity of the mesophotic zone. The effects of ocean acidification on food availability in the mesophotic zone could therefore over impose on those predicted as a consequence of the thermocline deepening under water warming scenarios $^{39}$.

The effects of ocean acidification on growth vary between calcifying organisms and non-calcifying organisms as well as amongst different calcifying taxa ${ }^{29}$. Among calcifying organisms, acidification can have a negative effect on calcifying algae and corals, but shows a less pronounced negative effect on coccolithophores, molluscs and echinoderms ${ }^{33}$. It has been hypothesized that deep-water corals' calcification in the Mediterranean Sea might have already declined by 
up to $50 \%$ as a consequence of anthropogenic-induced ocean acidification ${ }^{40}$. C. rubrum is known to be a long-lived species, but how 'long' its life span can be, is still controversial and object of present research. Its growth rates, determined using different independent approaches (Supplementary Table S2), can lead to ages of approximately 200 years ${ }^{1}$, placing C. rubrum among the longest-lived organisms in the Mediterranean benthic assemblages, possibly after only the millenary gold and black corals ${ }^{38}$. We show here that acidification did not determine a decrease of coral growth below levels observed in $s i t u^{41}$, but caused a significant decrease of calcification rates (when compared with the control samples). This result indicates that ocean acidification at levels predicted for different 2100 IPCC scenarios will further decrease the already very low growth rates of this centennial species. Altered carbonate chemistry can also directly affect the deposition and dissolution rates of the $\mathrm{CaCO}_{3}$ used for skeletal structures $^{42}$. Experimental and field studies suggest that calcification is affected in a wide range of marine calcifying taxa ${ }^{15}$. Variations in responses to acidification amongst calcifying organisms may depend on the mineral form of $\mathrm{CaCO}_{3}$ used by the organism, with the solubility and susceptibility increasing from low-magnesium calcite to aragonite and high-magnesium calcite ${ }^{15}$. C. rubrum has a Mg-rich calcite skeleton, so that consequences of acidification on its calcification could be relevant.

Skeletal accretion of C. rubrum displays two different patterns of growth, one related to sclerites deposition and a second one on the colony scleraxis, where a peripheral skeletogenic epithelium is responsible of the axial thickening ${ }^{43}$. The mineral microstructure of the axial skeleton presents micro-protuberances on the surface ${ }^{44}$. Our results indicate a significant decrease in relative production (as percentage of newly formed fluorescent sclerites) of the two types of sclerites (i.e., capstans and crosses) in apical fragments of colonies exposed to acidification, which was primarily affecting capstans. Here we found consistent results in short and long term experiments and the lack of resilience in the longer term exposure to low $\mathrm{pH}$ conditions. At the same time C. rubrum colonies showed a higher crosses/capstans ratio in acidified colonies. The increased proportion of small crosses could be explained as an adaptation of the colonies exposed to acidified conditions to preserve coenechimal stiffness, while limiting energetic costs of calcification (i.e., decreasing the production of larger capstan and skeletal structures $\left.{ }^{44}\right)$. Skeleton of colonies reared under control conditions grew with an organized smooth surface, but the surface of both axial skeleton and sclerites of colonies exposed to acidification became scraped and irregularly arranged (Figure 3 and 4, magnified details). Differences in fine-scale skeletal morphology among control and treated colonies were present in all the examined samples. Changes in crystal morphology as a response to changes in the saturation state, are consistent with previous studies on tropical corals $s^{4-46}$ and confirm the difficulties encountered by C. rubrum in the production of skeletal structures under increased $\mathrm{pCO}_{2}$ conditions. Altogether these results demonstrate that ocean acidification can affect not only calcification rates but also alter the patterns of biomineralization. Being sclerites production related to the biosynthesis of scleritin, biomineralization processes can be considered under genetic control ${ }^{47}$ and acidification could affect not only biocrystals surface but also modulate gene expression as suggested for scleractinians ${ }^{48}$. Marine organisms vary broadly in their responses to ocean acidification primarily because of the wide variety of processes affected (e.g., dissolution and calcification rates, growth rates, development and survival), making it challenging to predict how marine ecosystems will cope to decreased $\mathrm{pH}$. Although we cannot exclude that the observed effects of lower $\mathrm{pH}$ values on red coral growth, biomineralization and polyps' activity could change on interannual to decadal scale as a consequence of interactions with other environmental factors (e.g., interactions between acidification, temperature shifts and change in food sup$\mathrm{ply}^{21}$ ), our results suggest that ocean acidification has the potential to negatively impact calcification, growth rates and feeding efficiency, with potentially negative effects on reproductive output and recruitment success.

Since precious corals of the genus Corallium are long-living species, a large portion of the populations currently inhabiting hard bottoms of mesophotic habitats worldwide will directly experience the reduced $\mathrm{pH}$ values predicted for the end of this century. The effects of acidification, as observed in our experiments, will thus be directly experienced by the present populations inhabiting mesophotic habitats, and will potentially contribute to the population fragmentation and increase the risk of potential extinction. As C. rubrum is a habitat-forming species able to shape the seascape architecture and to sustain a high biodiversity, the results of the present study let hypothesize that ocean acidification could have a severe impact on structural complexity and functioning of these mesophotic habitats.

\section{Methods}

We conducted 2 time-course experiments of different duration to explore short term and long term effects of ocean acidification. The first was run in spring 2011 and the second in spring 2012.

For the short term experiment apical branches of Corallium rubrum $(\mathrm{n}=45$, about $4 \mathrm{~cm}$ long with ca 200 polyps each) were collected from 45 different colonies at the Marine Protected Area of Portofino (Ligurian Sea, Italy). Fragments were placed in a plastic tank with seawater continuously filtered and maintained at in situ temperature $\left(\sim 13.5^{\circ} \mathrm{C}\right)$. Samples were transferred to the laboratory within $12 \mathrm{~h}$ and acclimated in the mesocosms for one week under stable conditions (i.e., temperature: $13.7 \pm 0.2^{\circ} \mathrm{C}$, salinity: $38.0 \pm 0.1$ ) before the experiment. Five coral branches of C. rubrum were placed in each mesocosm.

For the long-term experiment apical branches of Corallium rubrum $(n=63$, about $4 \mathrm{~cm}$ long, with ca 200 polyps each) (Supplementary Figure S1) were collected at the Marine Protected Area of Portofino (Ligurian Sea, Italy), at $40 \pm 0.5 \mathrm{~m}$ depth. Each branch was withdrawn from a different colony to minimize the impact of sampling and to provide the widest diversity of the C. rubrum populations inhabiting the cliff at the selected depth. Fragments were placed in a plastic tank with seawater continuously air bubbled and maintained at in situ temperature $\left(\sim 13.5^{\circ} \mathrm{C}\right)$ and salinity $(\sim 38.1)$. Samples were transferred to the lab within $12 \mathrm{~h}$ and acclimated for three weeks in the mesocosms under stable conditions (i.e., temperature: $13.51 \pm 0.11^{\circ} \mathrm{C}$, salinity: $38.26 \pm 0.25$ ) before the experiment. Seven coral branches of $C$. rubrum were placed in each mesocosm.

Experimental set-up. For both experiments nine mesocosms were filled with $6 \mathrm{~L}$ of $0.2-\mu \mathrm{m}$ pre-filtered seawater (collected in situ). The experimental design included 3 control mesocosms, 3 mesocosms exposed to a moderate increase in $\mathrm{pCO}_{2}$ and 3 mesocosms exposed to high $\mathrm{pCO}_{2}$ (respectively $\mathrm{A} 1 \mathrm{~B}$ and $\mathrm{A} 1 \mathrm{~F} 1$ scenarios ${ }^{25}$ ). Certified air- $\mathrm{CO}_{2}$ gas mixtures (Rivoira S.p.A.) with $372 \pm 15,734 \pm 30$ and $975 \pm$ $39 \mathrm{ppm} \mathrm{CO}_{2}$ were continuously bubbled in the control and the two treated mesocosms, leading to a mean $\mathrm{pH}$ of $8.09,7.88$ and 7.77 , respectively. RTM3 flow meters (Technologie Medicale S.A.S) were used to adjust the flow rate at $150 \mathrm{ml}$ $\mathrm{min}^{-1}$. All nine mesocosms were placed in a large tank in which water temperature, during the entire duration of the experiment terminated after 10 (short-term) and 45 days due to the occurrence of a major heatings which made unable the system to maintain in situ temperature. All colonies survived to the experiment after the cessation of the $\mathrm{CO}_{2}$ bubbling. During the entire duration of the experiment the systems were maintained at the in situ temperature values using a TECO SeaChill Chiller TR5. To ensure an homogeneous distribution of the temperature within the tank, two independent recirculation pumps $\left(480 \mathrm{~L} \mathrm{~h}^{-1}\right)$ were used. Mesocosms were shaded to reproduce in situ light conditions using an opaque cloth to reduce normal indoor irradiance (by $80 \%$ ) out of direct sunlight. Water within each mesocosm was continuously re-circulated and mechanically filtered at the rate of $190 \mathrm{~L} \mathrm{~h}^{-1}$. Each mesocosm was covered with a plastic wrap to facilitate equilibration between the gas mixtures and the experimental seawater and to minimize water evaporation. One sixth seawater renewal was made at the end of the acclimation period, i.e., just before starting the experiment. Coral colonies in each mesocosm were fed daily at $3 \mathrm{pm}$ with $5 \mathrm{~mL}$ of a concentrated solution of a mixture of Artemia salina nauplii and rotifers in filtered seawater. Density of food items was $\sim 2000$ rotifers and $\sim 30,000$ Artemia's nauplii per mesocosm per day.

Physical-chemical variables and carbonate parameters. Temperature and salinity values were measured with an YSI TDS conductivity meter. $\mathrm{pH}$ was determined using a Crison $\mathrm{pH}$ electrode/meter calibrated with NBS buffers (accuracy \pm 0.005 ).

Alkalinity was determined at the beginning (day 1), and at the end (day 10 or 45 , in the short- and long-term experiments, respectively) of the experiment (Supplementary Table S1) using an open-cell potentiometric titration procedure calibrated with certified alkalinity standards ${ }^{49}$. Seawater samples $(500 \mathrm{ml})$ for Total Alkalinity (TA), were added with $200 \mu \mathrm{l}$ of $50 \% \mathrm{HgCl}_{2}$ saturated solution to avoid any biological alteration and stored in the dark at $4{ }^{\circ} \mathrm{C}$ until analysis. TA was determined on $\sim 140 \mathrm{~g}$ subsamples using a titration system comprising of a $250 \mathrm{ml}$ open titration cell thermo-regulated at $25 \pm 0.1^{\circ} \mathrm{C}$, a Crison $\mathrm{pH}$ electrode/meter calibrated with certified 
DIN $19267 \mathrm{pH} / \mathrm{mV}$ standards $( \pm 0.5 \mathrm{mV})$ and a Crison Burette $1 \mathrm{~S}( \pm 0.001 \mathrm{ml})$. The accuracy of the titrations was $\pm 3 \mu \mathrm{mol} \mathrm{kg}{ }^{-1}$. Parameters of the carbonate system, including $\mathrm{pCO}_{2}, \mathrm{HCO}_{3}{ }^{-}$, and DIC concentrations, saturation of aragonite $(\Omega \mathrm{Ar})$ and calcite $(\Omega \mathrm{Ca})$ were calculated from the measured values of $\mathrm{pHNBS}$, TA, temperature, salinity, phosphate and silicate concentrations using the program $\mathrm{CO}_{2}$ Sys.xls $2011^{50}$. Physical-chemical variables and carbonate system parameters at the beginning and the end of the experiment in the three treatments are summarized in Supplementary Table S1.

Growth. Net growth rates of $C$. rubrum were determined using the buoyant weighing method, which has minimal effect on the physiology and health of the colonies ${ }^{21}$. Moreover, given the duration and grow rate of the branches, the method used resulted to be sufficiently sensitive to quantify the growth rates of the colonies. All coral branches were weighted remaining immersed into the mesocosms (Radwag bottomloading scale, repeatability $=0.03 \mathrm{mg}$ ). In addition, the dry weight of the axial skeleton, of the sclerites and of the total skeleton (i.e., axial skeleton plus sclerites) was also determined $( \pm 0.1 \mathrm{mg})$. Daily growth rates were calculated as the percentage weight difference (measured as buoyant weight) between the beginning and the end of the experiment, and normalized to the coral branch initial weight and the duration of the experiment. To calculate the mean basal diameter annual growth rate, first buoyant weights were converted into dry weights using the linear regression equation between buoyant weights and total (i.e., axial skeleton plus sclerites) dry skeleton weights ( $y=1.6318 \times, r=0.99$, Supplementary Figure S5). Subsequently, dry weights were converted to basal diameters using the following relationship ${ }^{51}$ :

$$
\mathrm{W}=0.086 \times \mathrm{G}^{2.918}
$$

where $\mathrm{W}=$ dry weight; $\mathrm{G}=$ basal diameter of the colony. Annual basal diameter growth rates were finally calculated by normalizing to the duration of the interval $(\mathrm{n}=10,30$ and 45 days) and multiplying by 365 .

Sclerites accretion. To detect the effects of increased $\mathrm{pCO}_{2}$ on the sclerites accretion of C. rubrum, a calcein labeling experiment was conducted. At the end of the experiment, three colonies from each mesocosm were transferred in separated aquaria kept under same conditions of temperature and $\mathrm{pH}$ such as from where the colonies were withdrawn. Treated and untreated coral branches were exposed to calcein (Sigma C-0875) with a final concentration of $10 \mathrm{mg} \mathrm{L}^{-1}$ for $120 \mathrm{~h}$. Subsequently, their apical parts were soaked in a $12 \%$ solution of sodium hypochlorite for $24 \mathrm{~h}$ or until all organic material was removed ${ }^{52}$ (i.e., only the axial skeleton and sclerites remained). The sclerites were then rinsed several times with reagent grade water (MilliQ), mounted on slides and analyzed under epifluorescence microscopy (excitation filter 450-490 nm) for total and fluorescent capstan and cross sclerites counting (Supplementary Figure S1). Only apical parts were analyzed since it is known that $C$. rubrum calcifies more rapidly in its apical regions where the sclerites are directly incorporated to form the medullar part of the axial skeleton ${ }^{53}$. The relative abundance of fluorescent (cross and capstan) sclerites was used as an estimate of newly-accreted calcium carbonate skeletal elements. Values of the fluorescent cross to capstan sclerites ratio were used to evaluate eventual differences in the production of the two different skeleton elements under the different $\mathrm{pCO}_{2}$ treatments.

Skeletal morphology. The effect of increased $\mathrm{pCO}_{2}$ on Ca deposition was assessed through the observation of skeletal subsamples under a Scanning Electron Microscope (SEM) to analyze the fine-scale skeletal morphology. At the end of the experiment, one colony was withdrawn from each mesocosm and apical branches of the colonies were treated to remove all organic material using the same method adopted for fluorescent sclerites analyses. Skeletal subsamples were mounted on aluminum stubs using carbon adhesive tabs and coated with gold/palladium (Au/Pd) for five minutes using a Polaron Range sputter coater. SEM observations were conducted with a Philips ${ }^{\circledR}$ XL 20 microscope to assess the presence of skeletal malformation or dissolution at low $\mathrm{pH}$.

Polyps' activity. Polyps' activity (number of open vs. closed vs. partly open polyps) was measured twice a day (at $11 \mathrm{am}$ and $5 \mathrm{pm}$ ) for the entire duration of the experiment. Briefly, the activity of each colony was assessed by determining the state of activity of its polyps (and expressed as the prevailing state of the polyps expansion ${ }^{28}$ ). The latter was determined as follows: a value $=2$ was assigned to colonies with prevailing number of totally expanded polyp and tentacles; a values $=1$ was assigned to colonies with prevailing numbers of polyps or tentacles partially retracted and a value $=0$ was assigned to colonies dominated by totally retracted polyps. The overall assessment of polyps' activity in each mesocosm was calculated as the average of the five/seven colonies and reported as the percentage of the maximum expansion state. In addition, in the second experiment, the percentage of open polyps per each colony was also determined. To minimize effects on polyps' activity, the air- $\mathrm{CO}_{2}$ gas mixtures were pumped into the aquaria far from the coral fragments.

1. Teixidó, N., Garrabou, J. \& Harmelin, J. G. Low dynamics, high longevity and persistence of sessile structural species dwelling on mediterranean coralligenous outcrops. PLoS ONE 6, e23744.

2. Kipson, S. et al. Rapid biodiversity assessment and monitoring method for highly diverse benthic communities: A case study of mediterranean coralligenous outcrops. PLOS ONE 6, e27103.
3. Ballesteros, E. Mediterranean coralligenous assemblages: A synthesis of present knowledge. Oceanogr. Mar. Biol. Annu. Rev. 44, 123-195 (2006).

4. Costantini, F. et al. Deep-water Corallium rubrum (L., 1758) from the Mediterranean Sea: Preliminary genetic characterisation. Mar. Ecol. 31, 261-269 (2010).

5. Freiwald, A., Beuck, L., Rüggeberg, A., Taviani, M. \& Hebbeln, D. The white coral community in the central mediterranean sea revealed by ROV surveys. Oceanogr. 22, 58-74 (2010).

6. Garrabou, J. \& Harmelin, J. G. A 20-year study on life-history traits of a harvested long-lived temperate coral in the NW Mediterranean: Insights into conservation and management needs. J. Anim. Ecol. 71, 966-978 (2002).

7. Eriksson, B. K., Rubach, A. \& Hillebrand, H. Biotic habitat complexity controls species diversity and nutrient effects on net biomass production. Ecology $\mathbf{8 7}$, 246-254 (2006)

8. Levin, L., Etter, R., Rex, M., Gooday, A. \& Smith, C. Environmental influences on regional deep-sea species diversity. Annu. Rev. Ecol. Evol. Syst. 32, 51-93 (2001).

9. Danovaro, R. et al. Exponential decline of deep-sea ecosystem functioning linked to benthic biodiversity loss. Curr. Biol. 18, 1-8 (2008).

10. Hughes, T. P. Catastrophes, phase shifts, and large-scale degradation of a Caribbean coral reef. Science 265, 1547-1551 (1994)

11. Bruckner, A. W. Rate and extent of decline in Corallium (pink and red coral) populations: Existing data meet the requirements for a CITES Appendix II listing. Mar. Ecol. Prog. Ser. 397, 319-332 (2009).

12. Yesson, C. et al. Global habitat suitability of cold-water octocorals. J. Biogeogr. 39, 1278-1292 (2012).

13. Fabry, V., Seibel, B., Feely, R. \& Orr, J. Impacts of ocean acidification on marine fauna and ecosystem processes. ICES J. Mar. Sci. 65, 414-432 (2008).

14. Gattuso, J.-P. \& Hansson, L. Ocean Acidification. 352 pp (Oxford University Press, 2011).

15. Ries, J. B. Skeletal mineralogy in a high- $\mathrm{CO}_{2}$ world. J. Exp. Mar. Biol. Ecol. 403 , 54-64 (2011)

16. Iglesias-Rodriguez, M. D. et al. Phytoplankton calcification in a high- $\mathrm{CO}_{2}$ world. Science 320, 336-340 (2008).

17. Ries, J. B., Cohen, A. L. \& McCorkle, D. C. Marine calcifiers exhibit mixed responses to $\mathrm{CO}_{2}$-induced ocean acidification. Geology 37, 1131-1134 (2009).

18. Doney, S. C., Fabry, V. J., Feely, R. A. \& Kleypas, J. A. Ocean Acidification: The Other $\mathrm{CO}_{2}$ Problem. Annu. Rev. Mar. Sci. 1, 169-192 (2009).

19. Guinotte, J. M. \& Fabry, V. J. Ocean acidification and its potential effects on marine ecosystems. Ann. N. Y. Acad. Sci. 1134, 320-342 (2008).

20. Movilla, J. et al. Calcification reduction and recovery in native and non-native Mediterranean corals in response to ocean acidification. J. Exp. Mar. Biol. Ecol. 438, 144-153 (2012).

21. Form, A. U. \& Riebesell, U. Acclimation to ocean acidification during long-term $\mathrm{CO} 2$ exposure in the cold-water coral. Lophelia pertusa. Glob. Change Biol. 18, $843-853$ (2012)

22. Benton, T. G., Solan, M., Travis, J. M. J. \& Sait, S. M. Microcosm experiments can inform global ecological problems. Trends Ecol. Evol. 22, 516-521 (2007).

23. Touratier, F. \& Goyet, C. Impact of the Eastern Mediterranean Transient on the distribution of anthropogenic $\mathrm{CO}_{2}$ and first estimate of acidification for the Mediterranean Sea. Dee-Sea Res. Part I: Oceanogr. Res. Pap. 58, 1-15 (2011).

24. Lejeusne, C., Chevaldonné, P., Pergent-Martini, C., Boudouresque, C. F. \& Pérez, T. Climate change effects on a miniature ocean: the highly diverse, highly impacted Mediterranean Sea. Trends Ecol. Evol. 25, 250-260 (2010).

25. IPCC. Climate change 2007: the physical science basis. Contribution of Working Group I to the Fourth Assessment Report of the Intergovernmental Panel on Climate Change (eds Solomon, S. et al.) 996 pp (Cambridge University Press, 2007).

26. Vezzulli, L. et al. Vibrio infections triggering mass mortality events in a warming Mediterranean Sea. Environ. Microbiol. 12, 2007-2019 (2010).

27. Danovaro, R. et al. Sunscreens cause coral bleaching by promoting viral infections. Environ. Health Perspect. 116, 441-447 (2008).

28. Torrents, O., Tambutté, E., Caminiti, N. \& Garrabou, J. Upper thermal thresholds of shallow vs. deep populations of the precious Mediterranean red coral Corallium rubrum (L.): Assessing the potential effects of warming in the NW Mediterranean. J. Exp. Mar. Biol. Ecol. 357, 7-19 (2008).

29. Hall-Spencer, J. M. et al. Volcanic carbon dioxide vents show ecosystem effects of ocean acidification. Nature 454, 96-99 (2008).

30. Rodolfo-Metalpa, R. et al. Coral and mollusc resistance to ocean acidification adversely affected by warming. Nature Clim. Change 1, 308-312 (2011).

31. Fabricius, K. E. et al. Losers and winners in coral reefs acclimatized to elevated carbon dioxide concentrations. Nature Clim. Change 1, 165-169 (2011).

32. Garrard, S. et al. Biological impacts of ocean acidification: a postgraduate perspective on research priorities. Mar. Biol. published online doi: 10.1007/ s00227-012-2033-3.

33. Kroeker, K. J., Kordas, R. L., Crim, R. N. \& Singh, G. G. Meta-analysis reveals negative yet variable effects of ocean acidification on marine organisms. Ecol. Lett. 13, 1419-1434 (2010)

34. Dauphin, Y. Mineralizing matrices in the skeletal axes of two Corallium species (Alcyonacea). Comp. Biochem. Physiol. Part A Mol. Integr. Physiol. 145, 54-64 (2006).

35. Thresher, R. E., Tilbrook, B., Fallon, S., Wilson, N. C. \& Adkins, J. Effects of chronic low carbonate saturation levels on the distribution, growth and skeletal 
chemistry of deep-sea corals and other seamount megabenthos. Mar. Ecol. Prog. Ser. 442, 87-96 (2011).

36. Linares, C. et al. Marine Protected Areas and the conservation of long-lived marine invertebrates: The Mediterranean red coral. Mar. Ecol. Prog. Ser. 402, 69-79 (2010).

37. Previati, M., Scinto, A., Cerrano, C. \& Osinga, R. Oxygen consumption in Mediterranean octocorals under different temperatures. J. Exp. Mar. Biol. Ecol. 390, 39-48 (2010).

38. Cerrano, C. et al. Gold coral (Savalia savaglia) and gorgonian forests enhance benthic biodiversity and ecosystem functioning in the mesophotic zone. Biodivers. Conserv. 19, 153-167 (2010).

39. Coma, R. et al. Consequences of a mass mortality in populations of Eunicella singularis (Cnidaria: Octocorallia) in Menorca (NW Mediterranean). Mar. Ecol. Prog. Ser. 327, 51-60 (2006).

40. Maier, C., Watremez, P., Taviani, M., Weinbauer, M. G. \& Gattuso, J. P. Calcification rates and the effect of ocean acidification on Mediterranean cold-water corals. Proc. R. Soc. B Biol. Sci. rspb.2011.1763 (2011).

41. Marschal, C., Garrabou, J., Harmelin, J. G. \& Pichon, M. A new method for measuring growth and age in the precious red coral Corallium rubrum (L.). Coral Reefs 23, 423-432 (2004).

42. Gattuso, J. P. \& Buddemeier, R. W. Calcification and $\mathrm{CO}_{2}$. Nature 407, 311-313 (2000).

43. Allemand, D. \& Grillo, M. C. Biocalcification mechanisms in gorgonians. 45Ca uptake and deposition by the mediterranean red coral Corallium rubrum. J. Exp. Zool. 292, 237-246 (1992).

44. Cohen, A. L. \& Holcomb, M. Why corals care about ocean acidification: uncovering the mechanism. Oceanogr. 22, 118-127 (2009).

45. Cohen, A. L., McCorkle, D. C., De Putron, S., Gaetani, G. A. \& Rose, K. A. Morphological and compositional changes in the skeletons of new coral recruits reared in acidified seawater: Insights into the biomineralization response to ocean acidification. Geochem. Geophys. Geosyst. 10, Q07005 (2009).

46. Ries, J. B., Cohen, A. L. \& McCorkle, D. C. A nonlinear calcification response to $\mathrm{CO}_{2}$-induced ocean acidification by the coral. Oculina arbuscula Coral Reefs 29, 661-674 (2010).

47. Debreuil, J. et al. Comparative analysis of the soluble organic matrix of axial skeleton and sclerites of Corallium rubrum: Insights for biomineralization. Comp. Biochem. Physiol. Part B Biochem. Mol. Biol. 159, 40-48 (2011).

48. Kaniewska, P. et al. Major cellular and physiological impacts of ocean acidification on a reef building coral. PLoS ONE 7, e34659 (2012).

49. Dickson, A. G., Sabine, C. L. \& Christian, J. R. Guide to best practices for ocean $\mathrm{CO}_{2}$ measurements Vol. 3 (PICES Special Publication, 2007).
50. MS Excel Program Developed for $\mathrm{CO}_{2}$ System Calculations. ORNL/CDIAC-105a Carbon Dioxide Information Analysis Center (Oak Ridge National Laboratory, US Department of Energy, Oak Ridge, Tennessee, 2006).

51. Tsounis, G., Rossi, S., Gili, J. M. \& Arntz, W. E. Red coral fishery at the costa brava (NW Mediterranean): Case study of an overharvested precious coral. Ecosystems 10, 975-986 (2007)

52. Manzello, D. P. Coral growth with thermal stress and ocean acidification: Lessons from the eastern tropical Pacific. Coral Reefs 29, 749-758 (2010).

53. Debreuil, J. et al. Comparative analysis of the soluble organic matrix of axial skeleton and sclerites of Corallium rubrum: Insights for biomineralization. Comp. Biochem. Physiol. Part B Biochem. Mol. Biol. 159, 40-48 (2011)

\section{Acknowledgements}

This work has been conducted within the frame of the EU programmes DEVOTES (Development of innovative tools for understanding marine biodiversity and assessing good environmental status, funded under the 7th Framework Programme, 'The Ocean for Tomorrow' Theme ; grant agreement no. 308392, www.devotes-project.eu), and has been co-funded by the Flagship Project RITMARE - The Italian Research for the Sea coordinated by the Italian National Research Council and funded by the Italian Ministry of Education, University and Research within the National Research Program 2011-2013.

\section{Author contributions}

$\mathrm{CC}$ and $\mathrm{RD}$ conceived the study and planned the experiment. AP performed the sampling design and data analysis. UC, SB and CC performed the experiment and contributed to the analyses of the samples. All authors contributed to the writing of the manuscript.

\section{Additional information}

Supplementary information accompanies this paper at http://www.nature.com/ scientificreports

Competing financial interests: The authors declare no competing financial interests.

License: This work is licensed under a Creative Commons

Attribution-NonCommercial-NoDerivs 3.0 Unported License. To view a copy of this license, visit http://creativecommons.org/licenses/by-nc-nd/3.0/

How to cite this article: Cerrano, C. et al. Red coral extinction risk enhanced by ocean acidification. Sci. Rep. 3, 1457; DOI:10.1038/srep01457 (2013). 